
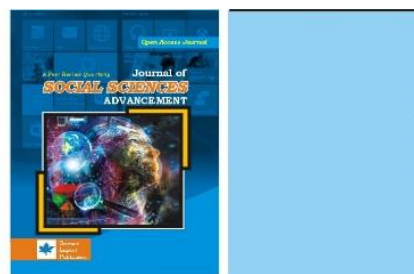

Journal of

Available Online

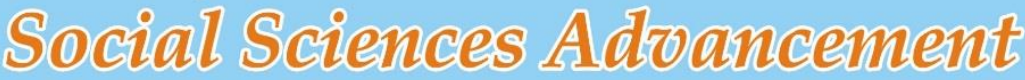

www.scienceimpactpub.com/jssa

\title{
CULTURAL DIFFERENCES AND PROBLEMS: A CASE OF INTERNATIONAL STUDENTS STUDYING IN A NORMAL UNIVERSITY IN NORTH CHINA
}

\author{
Sarfraz Aslam¹, Huma Akram², Khalida Parveen ${ }^{3}$ and Ali Usman Hali ${ }^{1}$ \\ ${ }^{1}$ School of Education, Shaanxi Normal University, Xian, China \\ ${ }^{2}$ School of Education, Northeast Normal University, Changchun, China \\ ${ }^{3}$ Faculty of Education, Southwest University, Chongqing, China
}

\begin{abstract}
International education has become an essential component of Chinese universities, and its importance is growing as a result of government funding. Academic exchange and collaboration with international universities are becoming more relevant in Chinese universities. This research aimed to develop a holistic understanding of international students' perceptions of socioeconomic, cultural, and intellectual issues in China. The study was qualitative, and semi-structured interviews were conducted. Five international students were recruited from different schools of the normal university, and all were from different countries. The overall cultural difference did not affect their life in china. The learning environment in a normal university was good-Chinese Language, a big problem everyone suffered. Availability of English language instructions in the university offices, canteens, etc. found very low. Course instructions need to improve. English taught programs should have full access to English Teaching Learning. Chinese and International student's classes should be together for better interaction and language learning.
\end{abstract}

Keywords: Cultural differences; International Students; Learning environment; Problems
*Corresponding Author: Khalida Parveen, Email: nicepak81@hotmail.com
(C) The Author(s) 2020.

\section{INTRODUCTION}

International education has become an essential component of Chinese universities, and its importance is growing as a result of government funding. Academic exchange and collaboration with international universities are becoming more relevant in Chinese universities. The world-class universities in China are notable because they attract many international students, have signed agreements with more international universities, and encourage international trade in higher education. To cope with the international knowledge-based economy, China has begun to participate in higher education imports and export to society and market growth (Thomson et al., 2006). The World Trade Organization (WTO) has influenced the Chinese higher education sector, and China is closing the gap between Chinese higher education and higher education in developing countries, with Chinese higher education institutes introducing advanced teaching resources (Li \& Zhao, 2010, p.1)

Economic changes are expected to increase international students' opportunities to study in China, and the Chinese government is encouraging education for international students. Joseph stated that since the 1980s, globalization, marketization, and quality/efficiency-driven transformations have resulted in systemic and qualitative shifts in education and policy, including a rising focus on "lifelong learning for everyone" or "cradle to grave" learning and the information economy in the global community.

Humans' physical needs are just one part of our life; the cognitive, mental, and moral needs are the second, and even more significant aspect of our existence. Education helps to meet all of these requirements. In reality, advances in knowledge and education have fueled material change throughout history. Those societies that recognized this and continued to succeed in educational fields were also world leaders (Ahmed, 2000).

According to Roslyn kunin and Associates Inc. (2009), Students who study abroad are well-known for their economic achievements (Ozer, 2016). With the rise of Chinese universities in international rankings, there has been a similar rise in students coming to China to study. China now has many international students, and this number is expected to grow in the future (Koehne, 2005). Top Chinese universities such as Zhejiang, Peking, and Tsinghua accept more than 3,000 international students each year.

The University of Nottingham and Zhejiang Wanli University's operation in Ningbo, the Xi'an Jiaotong-Liverpool University collaboration in Suzhou, and the University of Shanghai for Science and Technology's collaboration with a group of nine UK universities known as the Sino-British College in Shanghai are the least controversial. China's aggressive efforts to transform itself into an innovation industry require a significant rise in the number of foreign 
students, transforming the country into an education "center," according to a top Chinese education ministry official speaking at an international conference in Hong Kong. Meanwhile, according to recent official estimates, China now has 31 million higher education students, a 35\% rise in five years. There are reportedly about 260,000 international students in China, including those on short-term programs.

Researchers have worked to enhance international students' education in China, but there is a shortage of students' perceptions of socioeconomic, cultural, and intellectual issues. In terms of realistic consequences, this study gives helpful ideas and a vivid picture of developing strategies for international students, being mindful of international students' needs, and providing guidance for faculty/staff working with international students.

\section{REVIEW OF THE LITERATURE}

Studying in a new country can be both thrilling and daunting for international students who must contend with a range of transition issues, including academic, sociocultural, and psychological issues (Ward \& Kenney 1993). Difficulties may occur due to gaps in the linguistically defined discourse of intercultural and interpersonal contact and the cultural distance of the participants' communication patterns (Ward et al., 2001). In other words, the closer the student community is to the host culture, the smoother contact and transition would be (Mehdizadeh \& Scott, 2005).

When participating in cultural learning, they must attempt to make instructional changes in a new environment with varying patterns of teacher-student relationships, classroom environments, academic standards and goals, and different ideas and meanings of successful teaching and learning (Ward et al., 2001). Having fulfilled the English language entry criteria would not guarantee that they are well qualified to make adjustments to excel in the current school environment during the continuing transition period (Jepson et al., 2002).

Students fail to adapt to a modern learning community in which Socratic dialogical behaviors such as challenging, denouncing, refuting, complaining, discussing, and persuading are the norm (Major 2005, p. 85). Many aspects affect international students' cultural adaptation, including English language abilities, previous learning interactions, attitudes, cultural values, learning conceptions, personal characteristics, and motives (Berno \& Ward, 2004).

Since international students are the carriers of their society, a better knowledge of the essence of cultural variations will be evident (Xiexin, 2004). Individuals perceive and interpret culture in different ways. For example, Chunyan (2005, p.11) claims that Chinese education is founded on a family way of thinking, a very different culture from other cultures. Intercultural communication skills shift faster in students who travel overseas than in students who stay on campus, Pointed out by Williams (2005). Locals must consider international students' needs and help them learn Chinese culture and adjust to their new environment, contributing to mental illness (Zheng, 2010). For international students, social disparities in an alien world and new social patterns can create a daunting atmosphere, leading to several problems (Jiongmei \& Fan, 2010).

International students had the most trouble communicating with the university community, and these problems are significant indicators of international students' needs (Chu, et al., 2010; Akram, et al., 2020). Due to unfamiliarity with the host language, they often undergo language learning anxiety (Akram et al., 2019). On the other hand, interaction with faculty and other fellows is required for language practice and deeper comprehension to address the cultural divide that is a significant impediment to understanding a country's academic culture (Baohua, 2008).

Since international students' classrooms are multicultural, there are more opportunities for problems to arise as teachers and students connect (Jiongmei \& Fan, 2010). Other studies on cultural change, such as Xiexin (2004, p.91), focus on international students' general challenges in a new society, culture shock, and university management's response to China's issues. Dongfong (2005) conducted a thesis on cross-cultural communication issues in China, and the study party consisted of just eighteen students in the sense of cross-cultural communication in China. While cultural integration is a gradual process, and many of these problems will eventually vanish during the process of cultural change, it is assumed that international students face adjustment difficulties during their first semester at institutions of higher learning (Heggins \& Jackson, 2003).

\section{METHODOLOGY}

This research aimed to develop a holistic understanding of international students' perceptions of socioeconomic, cultural, and intellectual issues in China.

\section{Participants, Data Collection and Analysis}

Five participants were selected for semi-structured interviews to get international students' perceptions. Using a semi-structured protocol, we conducted face-to-face interviews with all participants. The interview guide was developed using a review of the literature, ideas, and input from a few international students. For example, some interview questions were: Why you chose to study in China, what you like and dislike about the Chinese education, what problems or barriers you have had at school, how do you spent your free time, how much interaction you have 
had with Chinese, whether you encountered any discrimination, what adjustment you made, and what your plan after graduation is. Interviews with all the participants were conducted in English.

All of the interviews took place in the residence of the participants. The length of each interview lasted from 20 minutes to 40 minutes. We audio-recoded all interviews with participant's consent. Later all the interviews were transcribed and used thematic analysis.

Table: Information of participants

\begin{tabular}{llclclc}
\hline Sr.No & Name & Gender & Nationality & Educational level & Major & Period of stay in China \\
\hline 1 & Saima & F & Pakistan & PhD & Genetics & 1 year \\
2 & Abdullah & M & Kenya & Master & Education & 2 year \\
3 & Lily & F & Myanmar & PhD & Education & 2 year \\
4 & Bahadar & M & Turkmenistan & Masters & Physics & 1 years \\
5 & John & M & Indonesia & PhD & Education & 1 year \\
\hline
\end{tabular}

Note. Pseudonyms were used in order to protect participants' identity

\section{Results}

The study's results are summarized in three (Figure 1) dimensions in this section:

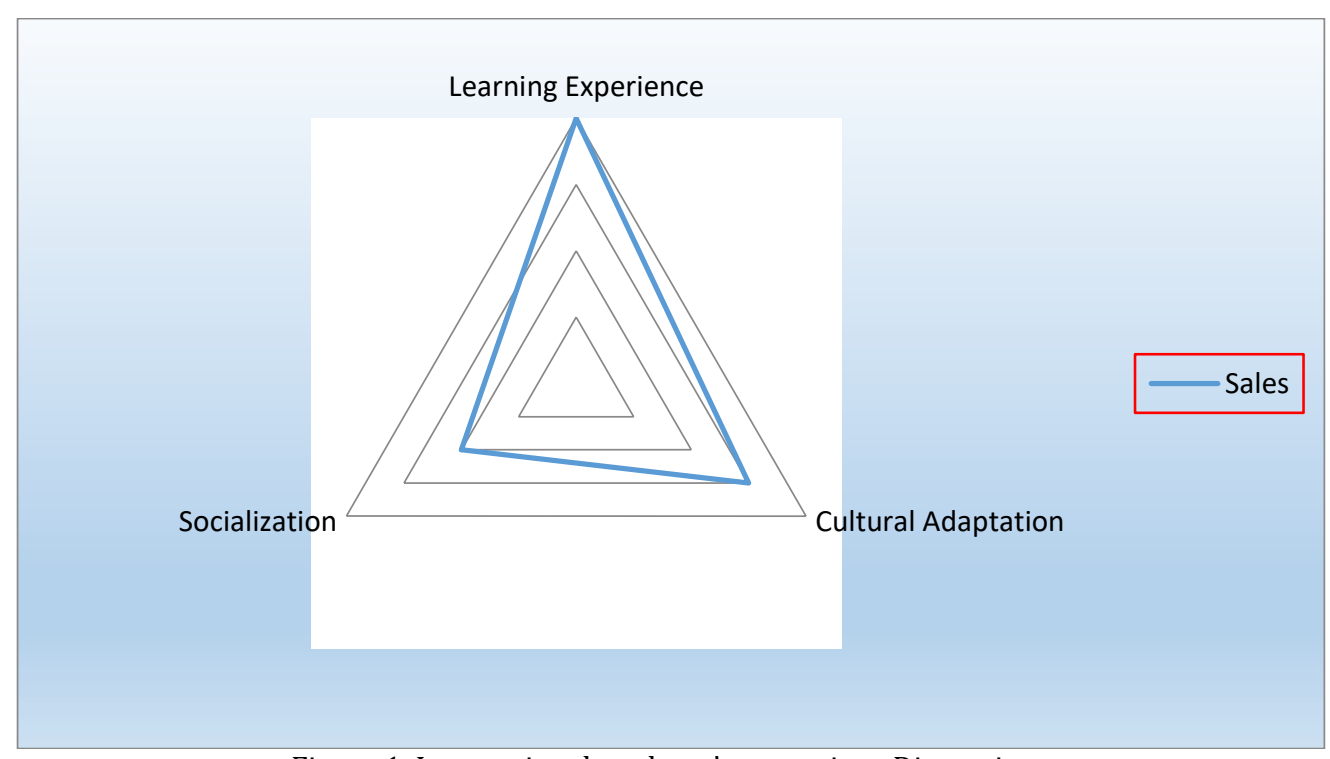

Figure 1. International students' perceptions Dimensions

According to this study's results, much of student satisfaction is related to their cultural adaptation level; that is, the more they respond to new cultures, the more optimistic their learning experience is. The majority of participants indicated that they had adapted well to the new learning conditions, though they also faced some difficulties in their learning. They maintained their cultural characteristics, such as high learning standards, achieving motivations, selfor parent-imposed learning stresses, a strong sense of competitiveness, and profound appreciation for teachers, as shown by their accounts.

On the one hand, they made every effort to adapt to the modern learning culture; on the other hand, they sought to make full use of learning skills learned in their home countries. The majority of participants demonstrated relatively high levels of satisfaction with their research at the host university. Their academic progress, language skills improvement, intellectual growth, academic accomplishments, development of cognitive, social, intercultural, interpersonal skills, learner trust, learner freedom, and incremental improvements in their learning conceptualizations all led to their fulfillment.

On an administrative basis, they were pleased with the educational content, realistic programs, conducive working practices, high-quality facilities, and efficient learning support networks. The majority of participants rated their lecturers as highly trained, skilled, polite, intelligent, patient, supportive, empathetic, competent, well-organized, polite, and understanding. A doctoral student characterized her university learning experiences as "outstanding.

Overall, students suggested social climate, and one student suggested a more substantial need for a more socially accessible environment. Other students suggested that there should be more chances for extracurricular and athletic events for local students. Others reported a need to build a comfortable atmosphere for international students to attend classes with Chinese students in the same classrooms. 
The social environment was particularly evident in the comments from a student: At shops and post offices, all signs and announcements are in Chinese; however, all notices must be written in English. Following graduation in China, a student commented. One student indicated that the simple management of students and teaching method in Chinese has some issues. Another male student commented that the services are satisfactory, but they should be better. A female student proposed a solution to an academic dilemma.

Another male international student claimed that close relationships between Chinese and international students are needed. Any respondents directly said that nothing was organized and that we had to go from office to office. One male student suggested that the Ph.D. and Masters Class should be separate because the Ph.D. students already experienced them, Master students do not feel freedom. A female from science suggested there should be proper coursework classes for them; do not rely only on home assignments.

\section{DISCUSSION}

This study was conducted to investigate international students' views regarding the educational environment's advantages and disadvantages by comparing and contrasting each other. They lead a contradictory academic life. e.g., they valued independent teaching but wanted teachers to pressure them. They enjoyed the friction-free learning environment, but they were uneasy when competition and high pressure were absent. The paradoxes perplexed international students who tried to cross boundaries into a grueling period of cultural and academic adaptations to reach their predetermined goals.

The paradoxes' negative aspects reduced their level of happiness with their learning experiences in China. Many of the underlying discourses of pedagogies are often taken for granted as the ethnic defaults' (Doherty 2006, p. 9), such as individual development, the learner participation discourse, group discussion, patterns of classroom interactions, assessment requirements, and criteria for writing assignments. International students are expected to adapt to the host learning environments in which they are studying. Regarding learning experiences, participants of the study showed satisfaction; this finding shows consistency with Akram and Yingxiu (2019). In the age of education globalization, lecturers do not seem to be expected to assume responsibility for responding to evolving classroom culture. According to McLaughlin (1995), it is professional reckless (p.112) to believe that only students must conform and accommodate when professors rely on retaining their roles.

\section{CONCLUSION}

Even though international students pay priority during the screening process to cultural cohesion and country proximity, it is conceivable for them to have a compliance problem. Universities should distribute literature with necessary information about the transition process, school system, financial system, rehabilitation facilities, university rules and regulations. More appropriate seminars and conferences with lectures by visiting scholars on current technologies and science can be organized to encourage students to learn innovative ideas.

\section{REFERENCES}

Akram, H., Kamran, M., \& Ahmad, N. (2020). An Examination of the Encountered Challenges of Pakistani International Students in China: A Case Study of First-Year Students. Pakistan Journal of Social Sciences, 40(4), $1567-1576$.

Akram, H., \& Yingxiu, Y. (2019). The Academic Experience of 1st Year International Students at Northeast Normal University: A Case Study of Northeast Normal University, Changchun, China. Education Quarterly Reviews, 2(1), 106-115. https://doi.org/10.31014/aior.1993.02.01.43

Akram, H., Junaid, M., \& Yingxiu, Y. (2019). Relationship Between Self-efficacy and Chinese Language Speaking Anxiety of International Students at Northeast Normal. Journal of Education and Practice, 10(2), 26-32. https://doi.org/10.7176/JEP/10-2-04

Baohua. Y. (2008). Cross-Cultural Adaptation and Second Language Acquisition: a study of international students in universities of the People's Republic of China. Ph.D. The University of Hong Kong.

Chunyan. S. (2005). A Study on Cultural Adaptation of Foreign Students in Beijing's Higher Education Institutions. Master thesis, Peking University Beijing, China. (In Chinese)

Doherty, C. (2006). Pedagogic identities on offer in a case of online internationalized education. AARE 2005 Education Research, 1-13.

Heggins, W. J., \& Jackson, J. F. (2003). Understanding the collegiate experience for Asian international students at a Midwestern research university. College Student Journal, 37(3), 379-392.

Jepson, M., Turner, T., \& Calway, B. (2002). The transition of international students into the post-graduate study: An incremental approach. In Australian Association for Research in Education (AARE), International Education Research Conference (1-5).

Jiongmei. H. Fan Z. (2010). Causes of Cultural Conflict in Central Asia and China of Foreign Students. Journal of Xinjiang Normal University 2010, 31 (3). 
Koehne, N. (2005). Positioning international education and international students: Multiple discourses and discursive practices. In International Conference of the Australian Association for Research in Education 2004: Doing the Public Good (1-17). Australian Association for Research in Education.

Li, X., \& Zhao, L. (2010). General Agreement on Trade in Services and higher education in China. Comparative and International Education, 39(3).

McLaughlin, D. (1995). Teaching overseas students and learning from them: A professional and moral dimension. Education Research and Perspectives, 22(1), 103.

Major, E. M. (2005). Co-national support, cultural therapy, and the adjustment of Asian students to English-speaking university culture. International Education Journal, 6(1), 84-95.

Mehdizadeh, N., \& Scott, G. (2005). Adjustment problems of Iranian international students in Scotland. International Journal of Educational Development, 6(4), 484-493.

Özer, M. (2016). The internationalization of higher education in Turkey: Realities, motivations, and opportunities. Insight Turkey, 18(4), 53-64.

Thomson, G., Rosenthal, D., \& Russell, J. (2006, October). Cultural stress among international students at an Australian university. In Australian International Education Conference (Vol. 10, pp. 1-8).

Ward, C., Bochner, S., \& Furnham, A. (2001). The psychology of culture shock, Routledge. Philadelphia, PA.

Williams, T. R. (2005). Exploring the impact of study abroad on students' intercultural communication skills: Adaptability and sensitivity. Journal of studies in international education, 9(4), $356-371$. http://dx.doi.org/10.1177/1028315305277681

Xin, X. (2004). Students of Cultural Differences and The University Crisis Management. Master Thesis, School of Government, Peking University, Beijing, China. (In Chinese) 